\title{
EFFECT OF EXERCISE GAMES ON THE PHYSICAL DEVELOPMENT OF MALE 5-6-YEAR-OLD STUDENTS AT PRESCHOOLS IN DONG THAP, VIETNAM
}

\author{
Nguyen Hung Dung, \\ Nguyen Toan Nang', \\ Nguyen Quang Vinh ${ }^{3 i}$ \\ ${ }^{1}$ Dong Thap University, \\ Vietnam \\ ${ }^{2}$ Tra Vinh University, \\ Vietnam \\ ${ }^{3} \mathrm{Ho}$ Chi Minh City University of \\ Physical Education and Sports, \\ Vietnam
}

\begin{abstract}
:
The study aims at examining the impact of exercise games on preschool children's physical development. The study took place in the school year 2018-2019 in Dong Thap, Vietnam. A total of 133 male preschool children aged from 5-6 years old from four public kindergartens took part in the study and were distributed in experimental group and control group. 30 exercise games were employed as the implementation tools. Although the physical fitness of both groups increased after the treatment, the physical fitness level of the experimental group gained higher improvement than that of the control group. The results indicate that the exercise games are effective in physical education in general and in improving children's physical fitness in particular.
\end{abstract}

Keywords: exercise games, physical fitness, preschool students, Dong Thap, VietNam

\section{Introduction}

Games in general play an important role in the life of young children. In educational context, they are also considered as one of the significant educational methods used for teaching children. In fact, at kindergartens, various games such as learning games, themed role-playing games, construction games and exercise games (EG) are used frequently. The EG mainly aims to motivate young children to participate in movement activities. Those movements can make children practice the motor skills. In

i Correspondence: email vinhqn@upes.edu.vn 
kindergartens, the EG can not only be a teaching tool to encourage children to be active, to feel comfortable with movements but also a form of physical education which helps children have comprehensive education. Importantly, the EG can be held anywhere and anytime. To achieve certain goal, teachers need to exploit all available equipment at the school to design appropriate games to encourage children to play. It is true that the EG at schools will help children have more opportunities to perform various body movements with their teacher and friends. These movements contribute to the development of physical fitness, intelligence and personalities of children.

In physical education (PE), game-based approach has been pointed out its benefits in various studies in recent years. For instance, Lavrin et al. (2019) conducted a study to investigate the effectiveness of the game Ringo in PE classes on students' level of physical fitness. By the end of the experimental program, the students in the experimental group gained a higher level of fitness than their peers in the control group. The findings of Ye et al. (2018) also reveal the positive effect of exergaming on the intervention group's BMI and musculo skeletal fitness.

It is evident that game-based approach, especially exercise games have its effectiveness on the children's level of physical fitness. Thus, the current study entitled "Effect of exercise games on the physical development of male 5-6-year-old students at preschools in Dong thap, Vietnam" was conducted with the hope that the findings will shed a light into the teaching of PE in Vietnamese kindergartens.

\section{Research design and method}

\subsection{Instruments}

The study was carried out with instruments of questionnaire, physical fitness tests and experimental data analysis.

\subsection{Participants}

A total of 133 male preschool children aged from 5-6 years old from four public preschools in Dong Thap, Vietnam participated in this study across the school year 20182019. In particular, 63 male children from two schools namely Hoa Sua and My Phu kindergartens were recruited to the experimental group and 70 male children from two other schools namely Tan Thuan Tay and Tinh Thoi kindergartens served as participants for the control group.

Another group of samples including 12 experts and teachers in PE also participated in the study. They were given a questionnaire which aimed at insisting their ideas on the selection of exercise games implemented in the study.

\subsection{The procedure of selecting exercise games}

To select the exercise games implemented in the experiment, two steps were carried out as follows. 
Step 1: Collect some games from different sources of researchers inside and outside Vietnam. For instance, some previous studies of different authors were reviewed and synthesized such as the study of Chimôppaêva E.V. (1986), Le Anh Tho (1995), Nguyen Anh Tuyet (2000), Tran Dong Lam, Dinh Manh Cuong (2005), Le Anh Tho (2014), Nguyen Thi Hieu et al. (2014), Nguyen Van Thanh (2017) and Nguyen Thi Thao (2018). Additionally, based on the PE curriculum for preschool children in Dong Thap province and the reality of the schools, the researchers decided to choose 35 games used for consultation from the expert group.

Step 2: Conduct a survey exploring ideas of experts and teachers in the field of physical education to have better selection of exercise games.

\section{Results and discussion}

\subsection{Results from questionnaire with a group of $\mathbf{1 2}$ experts for better selection of games} A questionnaire with 35 games was given to the group of experts and teachers in PE. To assure the reliability of the responses from the respondents, the questionnaire was delievered twice within the interval of one month. The questionnaire used the scale of Agree and Disagree for ease. To check the compatibility of the results from two times of the questionnaire, the Chi-square test $(\chi 2)$ was employed. The data of the two times of the survey are presented in Table 3.1 below.

Table 3.1: Results from two times of the survey on the selection of exercise games for preschool children

\begin{tabular}{|c|l|c|c|c|c|c|c|}
\hline \multirow{2}{*}{ No } & \multirow{2}{*}{ Games } & $\mathbf{1}^{\text {st }} \mathbf{t i m e} \mathbf{( n = 1 2 )}$ & $\mathbf{2}^{\text {nd }}$ time $\mathbf{( n = 1 2 )}$ & \multirow{2}{*}{$\boldsymbol{X}^{2}$} & \multirow{2}{*}{ sig } \\
\cline { 2 - 6 } & & $\mathbf{A g r e e}$ & $\mathbf{\%}$ & $\mathbf{A g r e e}$ & $\mathbf{\%}$ & \\
\hline 1 & Running relay & 8 & $\mathbf{6 6 . 6 7}$ & 8 & 66.67 & 00 & 1.00 \\
\hline 2 & Rabits finding cages & 11 & 91.67 & 11 & 91.67 & 00 & 1.00 \\
\hline 3 & Car and sparrow & 10 & 83.33 & 10 & 83.33 & 00 & 1.00 \\
\hline 4 & Group of three, group of six & 11 & 91.67 & 11 & 91.67 & 00 & 1.00 \\
\hline 5 & Delivering ball on the head & 10 & 83.33 & 10 & 83.33 & 00 & 1.00 \\
\hline 6 & Planting buds-planting trees & 12 & 100.00 & 12 & 100.00 & 00 & 1.00 \\
\hline 7 & Chasing & 7 & 58.33 & 8 & 66.67 & 1.32 & 0.25 \\
\hline 8 & Relay transfer & 10 & 83.33 & 10 & 83.33 & 00 & 1.00 \\
\hline 9 & The third odd one & 11 & 91.67 & 11 & 91.67 & 00 & 1.00 \\
\hline 10 & Flag snatching & 11 & 91.67 & 11 & 91.67 & 00 & 1.00 \\
\hline 11 & Cat and mouse game & 11 & 91.67 & 11 & 91.67 & 00 & 1.00 \\
\hline 12 & Running and changing position & 10 & 83.33 & 10 & 83.33 & 00 & 1.00 \\
\hline 13 & Running train & 12 & 100.00 & 12 & 100.00 & 00 & 1.00 \\
\hline 14 & Running relay in circle & 11 & 91.67 & 11 & 91.67 & 00 & 1.00 \\
\hline 15 & Running in triangle & 10 & 83.33 & 10 & 83.33 & 00 & 1.00 \\
\hline 16 & Running relay and throwing baskets & 11 & 91.67 & 11 & 91.67 & 00 & 1.00 \\
\hline 17 & Throwing a ball at a goal & 8 & $\mathbf{6 6 . 6 7}$ & 8 & 66.67 & 00 & 1.00 \\
\hline 18 & Ball relay & 12 & 100.00 & 12 & 100.00 & 00 & 1.00 \\
\hline 19 & Rolling the ball & 11 & 91.67 & 11 & 91.67 & 00 & 1.00 \\
\hline 20 & Throwing the ball into a basket & 10 & 83.33 & 10 & 83.33 & 00 & 1.00 \\
\hline
\end{tabular}


Nguyen Hung Dung, Nguyen Toan Nang, Nguyen Quang Vinh EFFECT OF EXERCISE GAMES ON THE PHYSICAL DEVELOPMENT OF

MALE 5-6-YEAR-OLD STUDENTS AT PRESCHOOLS IN DONG THAP, VIETNAM

\begin{tabular}{|l|l|c|c|c|c|c|c|}
\hline \hline 21 & Walking through the tunnel & 10 & 83.33 & 10 & 83.33 & 00 & 1.00 \\
\hline 22 & Catching frogs & 10 & 83.33 & 10 & 83.33 & 00 & 1.00 \\
\hline 23 & Supporting dwarf & 7 & 58.33 & 8 & 66.67 & 1.32 & 0.25 \\
\hline 24 & Catching fish by a net & 11 & 91.67 & 11 & 91.67 & 00 & 1.00 \\
\hline 25 & Hopping relay & 12 & 100.00 & 12 & 100.00 & 00 & 1.00 \\
\hline 26 & Catching crab and putting into bags & 11 & 91.67 & 11 & 91.67 & 00 & 1.00 \\
\hline 27 & Chanting while sawing wood & 10 & 83.33 & 10 & 83.33 & 00 & 1.00 \\
\hline 28 & Box jumping relay & 11 & 91.67 & 11 & 91.67 & 00 & 1.00 \\
\hline 29 & Jump right- jump fast & 10 & 83.33 & 10 & 83.33 & 00 & 1.00 \\
\hline 30 & Who pulls who is strong & 8 & $\mathbf{6 6 . 6 7}$ & 8 & 66.67 & 00 & 1.00 \\
\hline 31 & Dragon snake & 10 & 83.33 & 10 & 83.33 & 00 & 1.00 \\
\hline 32 & Crossing bridge relay & 10 & 83.33 & 10 & 83.33 & 00 & 1.00 \\
\hline 33 & Tug of war & 11 & 91.67 & 11 & 91.67 & 00 & 1.00 \\
\hline 34 & Crab crawing relay & 11 & 91.67 & 11 & 91.67 & 00 & 1.00 \\
\hline 35 & Crawing worm & 11 & 91.67 & 11 & 91.67 & 00 & 1.00 \\
\hline
\end{tabular}

The results from the questionnaires shown in Table 3.1 were not statistically different as all values were higher than $p$ value (sig. $>0.05$ ). Thus, there is compatibility between the results of two times of questionnaire. As can be seen in Table 3.1, only 30 games out of 35 can be selected with high percentage of agreement (80\%-100\%). It can be concluded that the excluded games were running relay, chasing, throwing a ball at a goal, supporting dwarf, who pulls who is strong.

\subsection{Evaluate the effectiveness of EG on the physical fitness level of male preschoolers}

\subsubsection{Planning the experiment}

The experiment was conducted to verify the effectiveness and feasibility of some exercise games on the development of physical fitness level of male preschool students in Dong Thap province. The necessity and effectiveness of the application of a number of games as proofs of the proposed hypothesis.

The duration of the experiment took place in the school year 2018-2019 with the participation of two groups as mentioned above.

The effectiveness of EG is evaluated by the use of some physical tests such as $10 \mathrm{~m}$ running (s), throwing sandbag with dominant hand $(\mathrm{cm})$, vertical jump test $(\mathrm{cm})$, continuously jump into 10 circles (s), sit-ups (cm), running around five poles (s).

\subsubsection{Conducting experiments and evaluate the effectiveness of exercise games on the} physical develoment of male preschool students (5-6 years old) in Dong Thap province

\subsubsection{Before the treatment}

In order to compare the mean values of the tests used for assessing the physical fitness of male preschool students aged 5-6 years old in the experimental group and the control group before the experiment, one-way ANOVA was employed to check the difference between the values. The results are presented in Table 3.2 below.

The results in Table 3.2 indicate that there was no statistical difference in the mean scores of the two groups before the implementation as all sig values are bigger than 0.05. 
It can be concluded that the level of physical fitness of the children from the experimental group and the control group is the same.

Table 3.2: Results from tests used for assessing the physical fitness of male preschool students between the experimental group and the control group

\begin{tabular}{|c|c|c|c|c|c|c|c|c|}
\hline \multirow[b]{2}{*}{ No } & \multirow[b]{2}{*}{ Evaluation tests } & \multicolumn{2}{|c|}{ Experimental group } & \multicolumn{2}{|c|}{ Control group } & \multirow[b]{2}{*}{$\mathbf{F}$} & \multirow[b]{2}{*}{ Sig } & \multirow[b]{2}{*}{ Post - hoc (LSD) } \\
\hline & & $\overline{X_{1}}$ & $\overline{X_{2}}$ & $\overline{X_{3}}$ & $\overline{X_{4}}$ & & & \\
\hline \begin{tabular}{|l|}
1 \\
\end{tabular} & $10 \mathrm{~m}$ running (s) & 2.83 & 2.84 & 2.82 & 2.80 & .188 & .904 & $\mu 1, \mu 2 \approx \mu 3, \mu 4$ \\
\hline 2 & $\begin{array}{l}\text { Throwing sandbag } \\
\text { with dominant hand }(\mathrm{cm})\end{array}$ & 571.20 & 561.94 & 561.90 & 568.57 & .161 & .922 & $\mu 1, \mu 2 \approx \mu 3, \mu 4$ \\
\hline 3 & Vertical jump test $(\mathrm{cm})$ & 98.22 & 97.56 & 98.69 & 95.39 & .468 & .705 & $\mu 1, \mu 2 \approx \mu 3, \mu 4$ \\
\hline 4 & $\begin{array}{l}\text { Continuously jump } \\
\text { into } 10 \text { circles (s) }\end{array}$ & 5.01 & 4.97 & 5.02 & 5.03 & .149 & .930 & $\mu 1, \mu 2 \approx \mu 3, \mu 4$ \\
\hline 5 & Sit-ups (cm) & 5.53 & 5.00 & 5.05 & 5.11 & .319 & .812 & $\mu 1, \mu 2 \approx \mu 3, \mu 4$ \\
\hline 6 & $\begin{array}{l}\text { Running around five } \\
\text { poles (s) }\end{array}$ & 9.02 & 8.98 & 9.06 & 9.06 & .097 & .962 & $\mu 1, \mu 2 \approx \mu 3, \mu 4$ \\
\hline
\end{tabular}

$\overline{X_{1}}, \mu 1$ : Hoa Sua kindergarten; $\overline{X_{2}}, \mu 2:$ My Phu kindergarten; $\overline{X_{3}} \mu 3$ : Tan Thuan Tay kindergarten; $\overline{X_{4}}, \mu 4:$ Tinh Thoi kindergarten
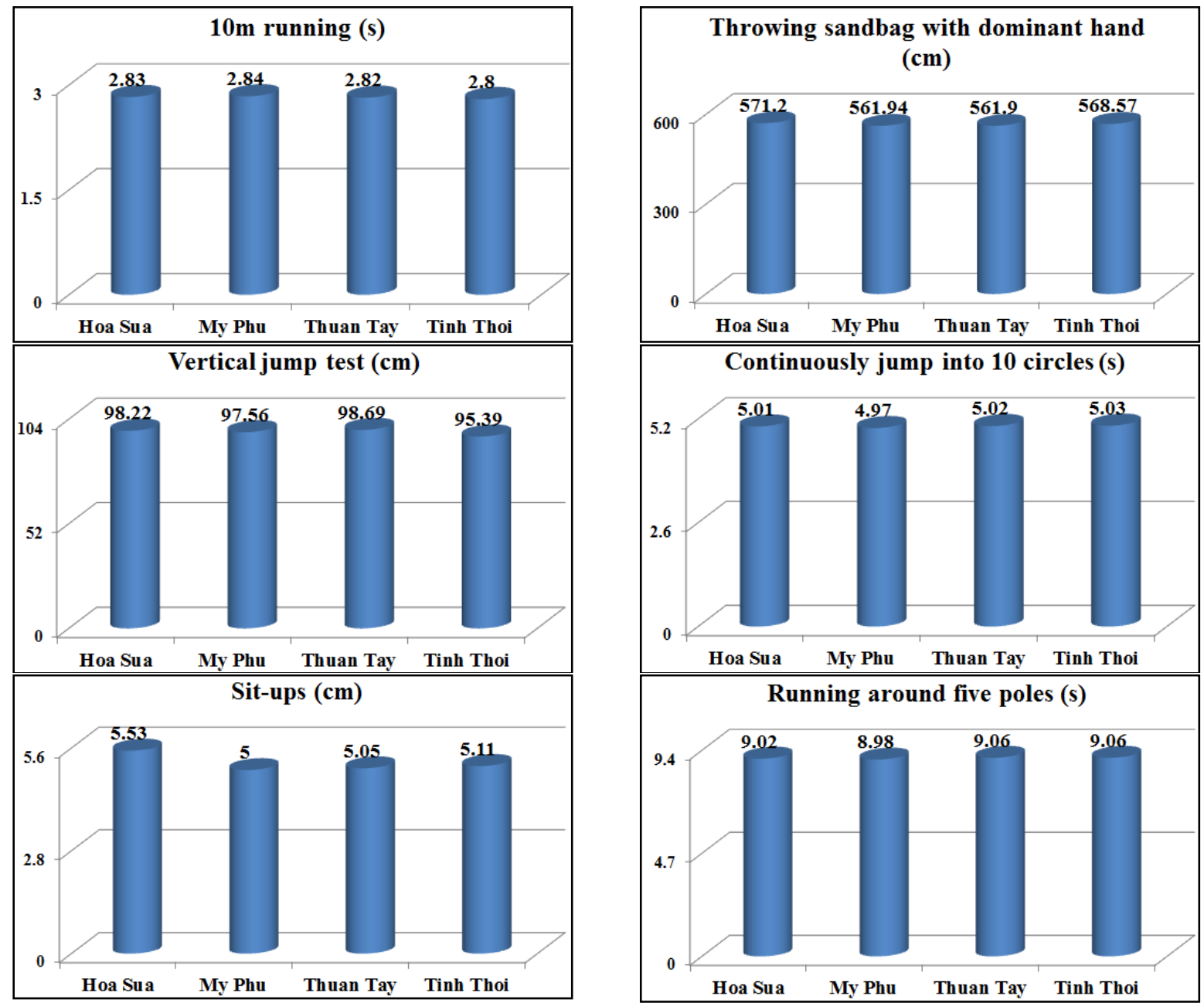

Figure 3.1: Comparison of mean scores of the physical fitness in the experimental group and the control group before the treatment 
The comparison of the physical fitness' mean scores of the two groups are shown in Figure 3.1 above.

\subsubsection{After the treatment}

To evaluate the effectiveness of exercise games on the physical fitness level of the male preschool children (5-6 years old) in the experimental group, paired sample t-test and growth rate test were used to compare the mean scores of each group before and after the experiment. The data are presented in Table 3.3 below.

Table 3.3: The results of physical fitness of the experimental group before and after the experiment

\begin{tabular}{|c|c|c|c|c|c|c|c|c|}
\hline & \multirow{2}{*}{ Tests } & \multicolumn{2}{|c|}{ Before the treatment } & \multicolumn{5}{|c|}{ After the treatment } \\
\hline & & $\bar{X}$ & $S$ & $\bar{X}$ & $S$ & $\overline{W \%}$ & $\mathbf{t}$ & $\mathbf{P}$ \\
\hline \multirow{7}{*}{ 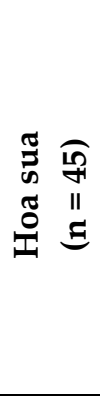 } & $10 \mathrm{~m}$ running $(\mathrm{s})$ & 2.83 & 0.22 & 2.55 & 0.19 & 10.50 & 26.43 & $<0.05$ \\
\hline & $\begin{array}{l}\text { Throwing sandbag with } \\
\text { dominant hand }(\mathrm{cm})\end{array}$ & 571.20 & 74.99 & 649.83 & 73.30 & 13.11 & 38.64 & $<0.05$ \\
\hline & Vertical jump test $(\mathrm{cm})$ & 98.22 & 10.66 & 105.24 & 10.58 & 6.98 & 18.99 & $<0.05$ \\
\hline & Continuously jump into 10 circles (s) & 5.01 & 0.32 & 4.60 & 0.30 & 8.58 & 30.89 & $<0.05$ \\
\hline & Sit-ups (cm) & 5.53 & 3.00 & 7.80 & 2.88 & 49.48 & 12.48 & $<0.05$ \\
\hline & Running around five poles (s) & 9.02 & 0.42 & 8.57 & 0.37 & 5.12 & 38.70 & $<0.05$ \\
\hline & \multicolumn{5}{|l|}{$\overline{W \%}$} & 15.63 & & \\
\hline \multirow{7}{*}{ 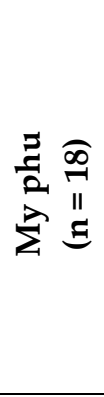 } & $10 \mathrm{~m}$ running $(\mathrm{s})$ & 2.84 & 0.21 & 2.57 & 0.20 & 9.82 & 22.52 & $<0.05$ \\
\hline & $\begin{array}{l}\text { Throwing sandbag with } \\
\text { dominant hand }(\mathrm{cm})\end{array}$ & 561.94 & 56.18 & 645.56 & 51.93 & 14.03 & 42.39 & $<0.05$ \\
\hline & Vertical jump test $(\mathrm{cm})$ & 97.56 & 10.44 & 106.83 & 10.12 & 9.19 & 25.79 & $<0.05$ \\
\hline & Continuously jump into 10 circles (s) & 4.97 & 0.27 & 4.56 & 0.23 & 8.55 & 11.14 & $<0.05$ \\
\hline & Sit-ups (cm) & 5.00 & 2.61 & 7.72 & 2.02 & 52.28 & 7.76 & $<0.05$ \\
\hline & Running around five poles (s) & 8.98 & 0.48 & 8.51 & 0.45 & 5.32 & 31.10 & $<0.05$ \\
\hline & \multicolumn{5}{|l|}{$\overline{W \%}$} & 16.53 & & \\
\hline
\end{tabular}

$\mathrm{df}=\mathrm{n}-1, \mathrm{t} 05=2.015,2.110$

Data presented in Table 3.3 show that after the treatment the mean scores of all physical tests of the experimental group was significant different with $\mathrm{P}<0.05$. It means that the level of physical fitness of the experimental group gained higher improvement after the treatment compared to that of the same group before the treatment. Specifically, the results of all criteria to evaluate physical fitness of male children aged from 5-6 years old at Hoa Sua kindergarten reached development with $t_{\text {caculated }}$ is bigger than $t_{05}=2.015$, the average growth rate $\overline{W \%}=15.63 \%$. In addition, the findings from My Phu kindergarten also reveal that the physical fitness of the preschool students gained higher growth after the treatment with $t_{\text {caculated }}$ is bigger than $t_{05}=2.015$, the average growth rate $\overline{W \%}=16.53 \%$. Among the criteria, sit-ups test received the highest development with $\overline{W \%}=49.48 \%$ for the children at My Phu kindergarten and $\overline{W \%}=52.29 \%$ for My Phu kindergarten 
respectively. It can be determined that the flexibility of the male preschool students aged 5-6 years old in the experimental group surged after the experiment.

The growth rate of all criteria on the physical fitness level of male preschool chidren from experimental group is presented in Figure 3.2 below.
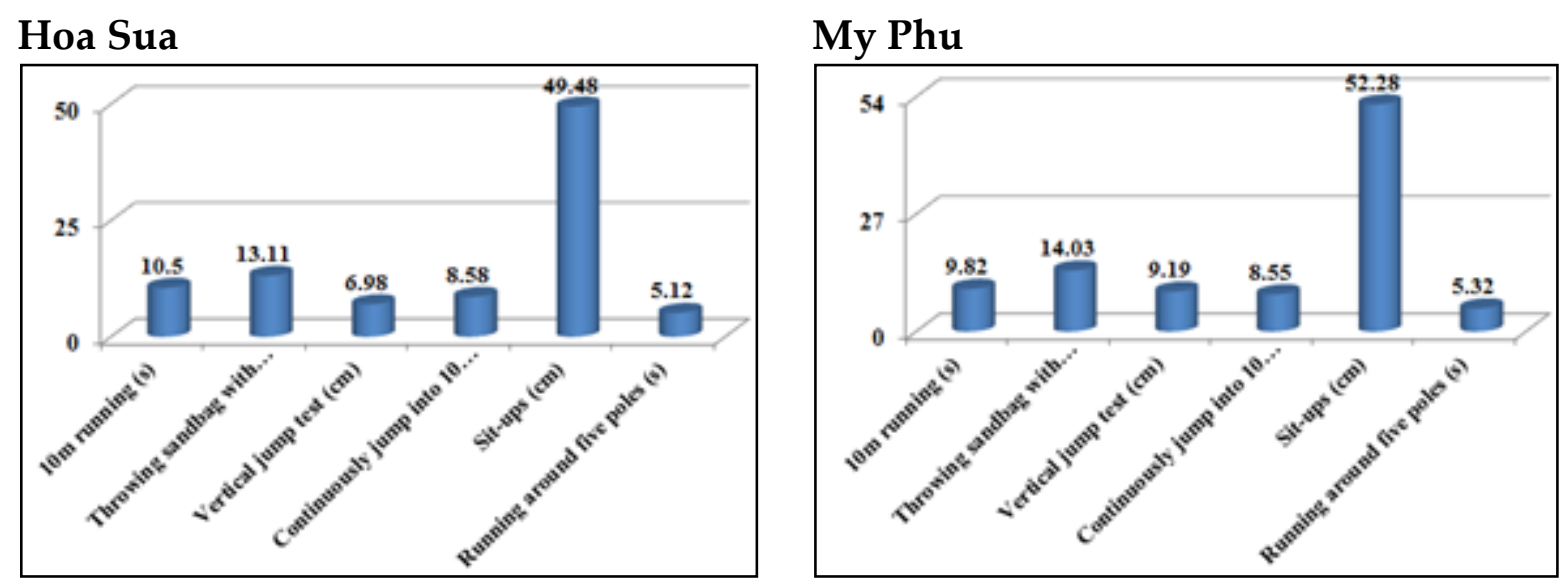

Figure 3.2: The growth rate of 5-6 male children's physical fitness of the experimental group after the treatment based on the physical tests

The results of physical fitness of 5-6 year-old male children of the control group based on the physical tests after the treatment are presented in Table 3.4 below.

Table 3.4: The results of 5-6 year-old male children's physical fitness in the control group based on the physical tests after the treatment

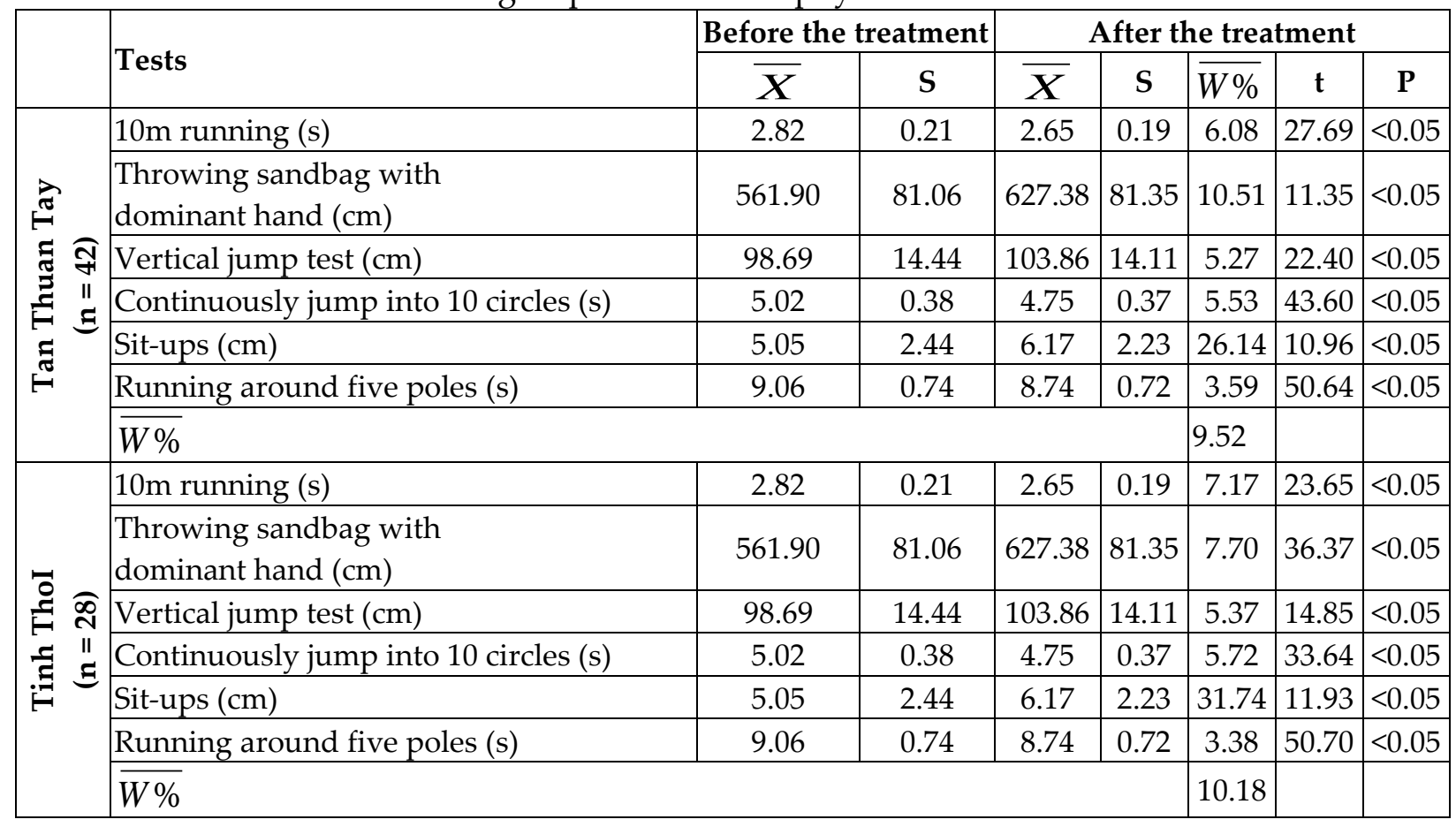

$\mathrm{df}=\mathrm{n}-1, \mathrm{t}_{05}=2.020,2.052$ 
As can be seen in Table 3.3, after the treatment the mean scores of all physical tests of the control group have mean difference with $\mathrm{P}<0.05$. It means that the level of physical fitness of the control group got enhancement after the treatment. In particular, the results of all criteria to evaluate physical fitness of male children aged from 5-6 years old at Tan Thuan Tay kindergarten reached progress level with $t_{\text {caculated }}$ is bigger than $t_{05}=2.020$, the average growth rate $\overline{W \%}=9.52 \%$. In addition, the mean scores from the male preschool students at Tinh Thoi kindergarten also indicate that the physical fitness of these children

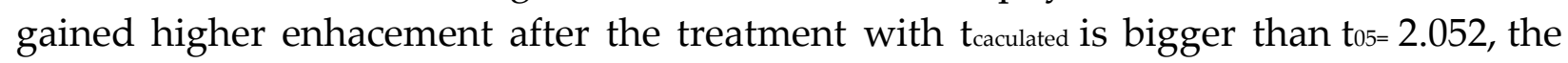
average growth rate $\overline{W \%}=10.18 \%$. Among the criteria, sit-ups test also gained the highest growth with $\overline{W \%}=26.14 \%$ for the children at Tan Thuan Tay kindergarten and $\overline{W \%}=$ $31.74 \%$ for Tinh Thoi kindergarten respectively. It can be inferred that the flexibility of the male preschool students aged 5-6 years old in the control group increased after the treatment.

The growth rate of all criteria on the physical fitness level of male preschool children from the control group is presented in Figure 3.3 below.

\section{Tan Thuan Tay}

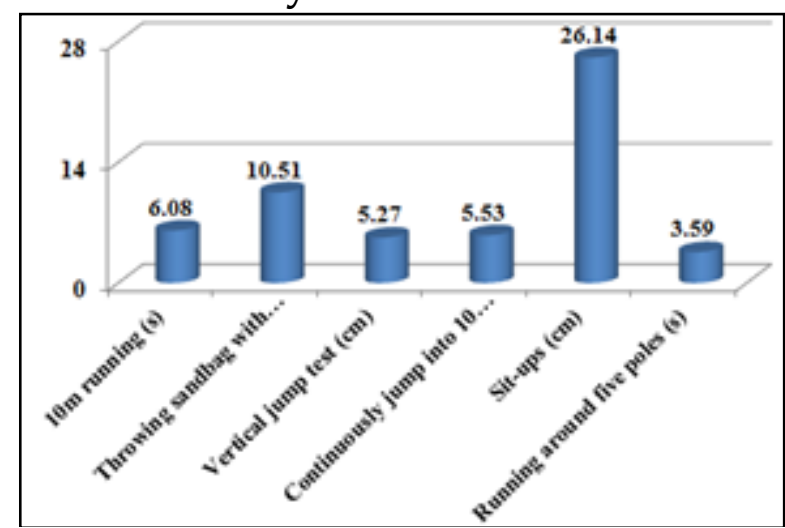

\section{Tinh Thoi}

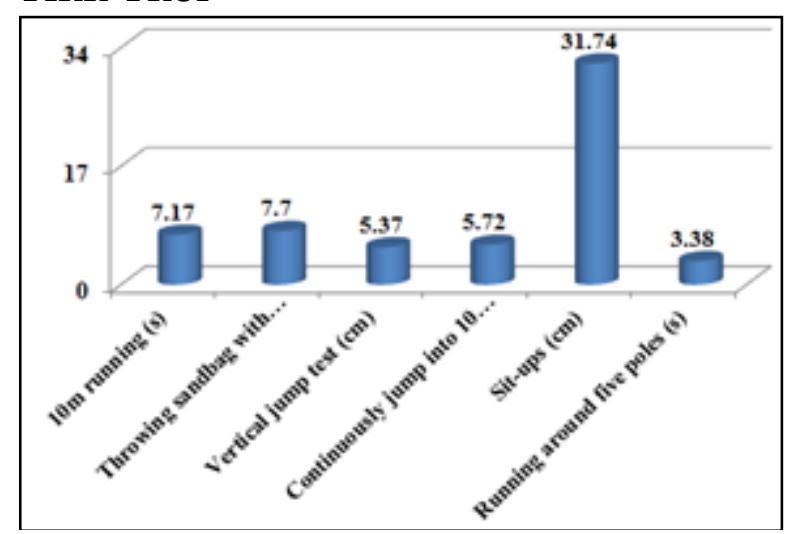

Figure 3.3: The growth rate of 5-6 male children's physical fitness in the control group after the treatment based on the physical tests

The results presented above indicate that after the treatment, the level of physical fitness of the experimental group and the control group all gain growth. Additionally, the values are statistical significance with $P<0.05$. The data reveal that the physical fitness of the experimental group gained higher growth than that of the control group. However, to make sure the results have scientific meaning, one-way ANOVA was employed. The results are shown in Table 3.5 below. 
Table 3.5: Comparison of growth rate between the experimental group and the control group

\begin{tabular}{|c|c|c|c|c|c|c|c|c|}
\hline & \multirow[b]{2}{*}{ Tests } & \multicolumn{2}{|c|}{ Experimental group } & \multicolumn{2}{|c|}{ Control group } & \multirow[b]{2}{*}{ F } & \multirow[b]{2}{*}{ Sig } & \multirow{2}{*}{$\begin{array}{l}\text { Post - hoc } \\
\text { (LSD) }\end{array}$} \\
\hline & & $\overline{W_{1}}$ & $\overline{\overline{W_{2}}}$ & $\overline{\overline{W_{3}}}$ & $\overline{\overline{W_{4}}}$ & & & \\
\hline 1 & $10 \mathrm{~m}$ running $(\mathrm{s})$ & 10.50 & 9.82 & 6.08 & 7.17 & 43.629 & .000 & $\mu 1, \mu 2>\mu 3, \mu 4$ \\
\hline 2 & $\begin{array}{l}\text { Throwing sandbag with } \\
\text { dominant hand }(\mathrm{cm})\end{array}$ & 13.11 & 14.03 & 10.51 & 7.70 & 15.159 & .000 & $\mu 1, \mu 2>\mu 3, \mu 4$ \\
\hline 3 & Vertical jump test $(\mathrm{cm})$ & 6.98 & 9.19 & 5.27 & 5.37 & 14.780 & .000 & $\mu 1, \mu 2>\mu 3, \mu 4$ \\
\hline 4 & Continuously jump into 10 circles (s) & 8.58 & 8.55 & 5.53 & 5.72 & 32.847 & .000 & $\mu 1, \mu 2>\mu 3, \mu 4$ \\
\hline 5 & Sit-ups (cm) & 49.48 & 52.28 & 26.14 & 31.74 & 4.067 & .000 & $\mu 1, \mu 2>\mu 3, \mu 4$ \\
\hline 6 & Running around five poles (s) & 5.12 & 5.32 & 3.59 & 3.38 & 84.694 & .000 & $\mu 1, \mu 2>\mu 3, \mu 4$ \\
\hline
\end{tabular}

Thoi kindergarten

The results in Table 3.5 show that after the intervention, the growth rate of the physical fitness of children from two kindergartens in the experimental group (Hoa Sua, $\mathrm{My} \mathrm{Phu}$ ) is more significant than their peers from the two schools in the control group (Tan Thuan Tay, Tinh Thoi). More comparison is shown in Figure 3.5 below.
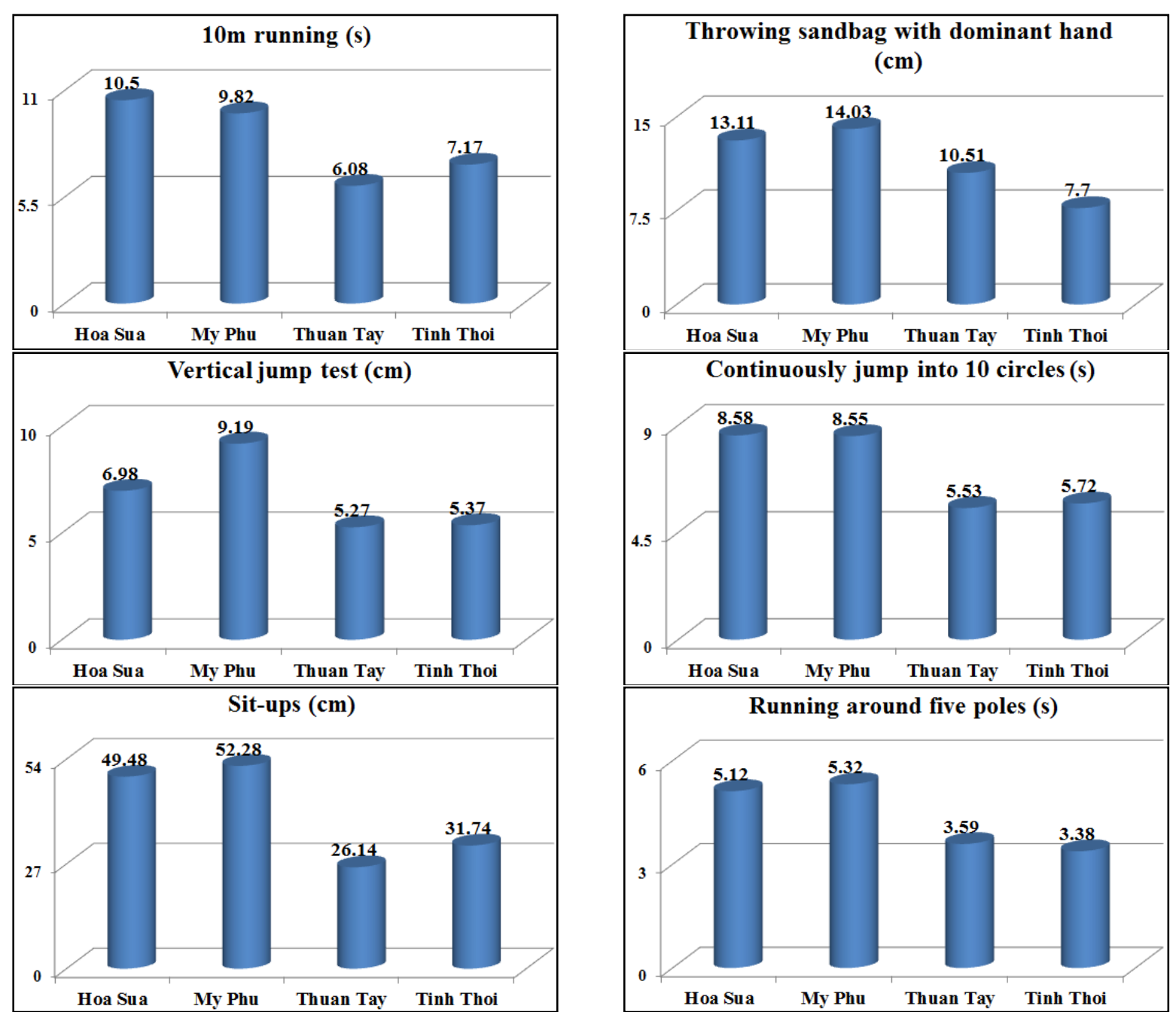

Figure 3.5: Comparison the growth rate between the experimental group and the control group 
The data analyzed above show that after the treatment the growth rate of the experimental group gains higher level than that of the control group. It indicates the positive impact of exercise games on the 5-6 male preschool students' physical fitness of the experimental group.

\section{Conclusion}

The implementation of exercise games exposed the level of physical fitness of male preschool students in the experimental group increased. After the experiment, the physical development of the participant children in the experimental group differs from that of the control group $(\mathrm{P}<0.05)$. The results of the current study also indicate that the speed, the endurance and the flexibility level of the children gained more progress. In sum, the results confirm the effectiveness of exercise games on the physical fitness level of the male preschool children aged 5-6 years old and these games should be included in the program of teaching PE for young children in the educational situation.

\section{Conflict of Interest Statement}

The authors declare no conflicts of interests.

\section{About the Authors}

Nguyen Hung Dung is a PhD candidate of Vietnam Sport Science Institute. His research interest is in physical education.

Nguyen Toan Nang is a P.E lecturer at Tra Vinh University.

Nguyen Quang Vinh is an associate professor in education. He is currently working at Ho Chi Minh city University of Physical education and Sports as chief of Academic Affairs Office.

\section{References}

Birinci Y. Z., Nimet Hasil Korkmaz \& Inci Ece Ozturk (2020). Can Exergames use as an educational tool in Physical education for cognitive, social and affective domains? International Journal of Scientific and Technological Research, Special Issue of Educational Sciences, Vol.6, No.6.

Chimôppaêva E. A. (1986). Exercise games for preschool students. Youth Publishing House.

Cocca A., Francisco Espino Verdugo, Luis Tomas Rodenas Cuenca \& Michael Cocca (2020). Effect of a game-based physical educational program, on physical fitness and mental health in elementary school children. International Journal of Environmental Research and Public Health, 17, 4883.

Ye S., Jung Eun Lee, David E Stodden and Zan Gao (2018). Impact of Exergaming on children's motor skill competence and health-related fitness: A quasi-experimental study. Journal of Clinial Medicine. 7, 261. 
Lavrin H. et al. (2019). Efficiency means the game Ringo the classroom Physical education. International Journal of Applied Exercise Physiology.

Le Anh Tho (1995). An investigation of traditional games in physical education for 4 year old children at kindergartens. Dissertaion in Education, Institute of Sports, Ha Noi.

Le Anh Tho (2014). Basic exercise games for kindergartens. Ha Noi sport Publishing.

Nguyen Thi Hieu, Nguyen Thi Thanh Giang, Nguyen Minh Huyen and Truong Dac Nguyen (2015). Selection of lesson plans for preschool children aged 5-6 years old to improve physical fitness. Vietnam Education Publishing House.

Tran Dong Lam, Dinh Manh Cuong (2005). Exercise games, Pedagogical University Publishing House.

Nguyen Van Thanh (2017). Application of game- based approach in teaching physical education to primary school students in Vinh city, Nghe An province. Dissertation in Education, Ho Chi Minh University of sports.

Nguyen Thi Thao (2018). Selection of exercise games to improve physical fitness and basic motor skills for preschool children at TH school. Education Journal, Special volume 8/2018, p 122-124.

Nguyen Anh Tuyet (2000). Games for young children. Women Publishing, Ha noi. 
Nguyen Hung Dung, Nguyen Toan Nang, Nguyen Quang Vinh

EFFECT OF EXERCISE GAMES ON THE PHYSICAL DEVELOPMENT OF

MALE 5-6-YEAR-OLD STUDENTS AT PRESCHOOLS IN DONG THAP, VIETNAM

Creative Commons licensing terms

Authors will retain the copyright of their published articles agreeing that a Creative Commons Attribution 4.0 International License (CC BY 4.0) terms will be applied to their work. Under the terms of this license, no permission is required from the author(s) or publisher for members of the community to copy, distribute, transmit or adapt the article content, providing a proper, prominent and unambiguous attribution to the authors in a manner that makes clear that the materials are being reused under permission of a Creative Commons License. Views, opinions and conclusions expressed in this research article are views, opinions and conclusions of the author(s). Open Access Publishing Group and European Journal of Physical Education and Sport Science shall not be responsible or answerable for any loss, damage or liability caused in relation to/arising out of conflict of interests, copyright violations and inappropriate or inaccurate use of any kind content related or integrated on the research work. All the published works are meeting the Open Access Publishing requirements and can be freely accessed, shared, modified, distributed and used in educational, commercial and non-commercial purposes under a Creative Commons attribution 4.0 International License (CC BY 4.0). 